\title{
Treatments to Optimize the Use of Artificial Insemination and Reproductive Efficiency in Beef Cattle under Tropical Environments
}

\author{
Ocilon Gomes de Sá Filho and José Luiz Moraes Vasconcelos \\ Departamento de Produção Animal, Faculdade de Medicina Veterinária e Zootecnia, UNESP, 18618-000 Botucatu, SP, Brazil \\ Correspondence should be addressed to José Luiz Moraes Vasconcelos, vasconcelos@fca.unesp.br
}

Received 11 May 2010; Revised 27 August 2010; Accepted 30 September 2010

Academic Editor: Ali Honaramooz

Copyright ( 2011 O. G. Sá Filho and J. L. M. Vasconcelos. This is an open access article distributed under the Creative Commons Attribution License, which permits unrestricted use, distribution, and reproduction in any medium, provided the original work is properly cited.

\begin{abstract}
Bos indicus cattle, the preferred genetic group in tropical climates, are characterized by having a lower reproductive efficiency than Bos taurus. The reasons for the poorer reproductive efficiency of the Bos indicus cows include longer lengths of gestation and postpartum anestrus, a short length of estrous behavior with a high incidence of estrus occurring during the dark hours, and puberty at older age and at a higher percentage of body weight relative to mature body weight. Moreover, geography, environment, economics, and social traditions are factors contributing for a lower use of reproductive biotechnologies in tropical environments. Hormonal protocols have been developed to resolve some of the reproductive challenges of the Bos indicus cattle and allow artificial insemination, which is the main strategy to hasten genetic improvement in commercial beef ranches. Most of these treatments use exogenous sources of progesterone associated with strategies to improve the final maturation of the dominant follicle, such as temporary weaning and exogenous gonadotropins. These treatments have caused large impacts on reproductive performance of beef cattle reared under tropical areas.
\end{abstract}

\section{Introduction}

In tropical climates, most beef cattle herds rear Bos indicus cattle due to their greater capacity to adapt to environmental challenges of climate and disease. Despite this adaptation, Bos indicus cattle have some particular reproductive characteristics that contribute to a poorer reproductive efficiency of Bos indicus cows. The use of artificial insemination (AI) after estrus detection may be limited in tropical areas due to the fact that Bos indicus cattle have a short length of estrous behavior with a high incidence of estrus occurring during the dark hours [1]. Moreover, compared with Bos taurus, Bos indicus cows have longer lengths of gestation and postpartum anestrus [2], making it difficult to adhere to a $365 \mathrm{~d}$ calving interval even in ranches using natural service and resulting in a large amount of cows calving at end of the calving season and having less time with chance to become pregnant during the subsequent breeding season (BS). These challenges are more critical in primiparous cows in pasture management systems $[3,4]$ because the intake of nutrients during the postpartum period is not sufficient to meet requirements for growth as well as lactation. As a result of the poor pregnancy rates in primiparous cows, many producers maintain nonpregnant primiparous cows in their herds to be inseminated during the subsequent BS, which contributes to reduce the profitability of cow-calf enterprises. Besides these differences regarding to the estrous behavior and anestrus length in postpartum cows, Bos indicus heifers reach puberty older and at a higher percentage of body weight relative to mature body weight than Bos taurus heifers [5], resulting in a lower proportion of pubertal females at the beginning of BS and lesser pregnancy rates $[6,7]$.

Other differences between Bos indicus and Bos taurus cattle, including ovarian follicular/corpus luteum sizes [1, $8]$, amount of follicles before divergence $[9,10]$, follicular diameter at divergence $[11,12]$, and size of dominant follicle at acquisition of ovulatory capacity $[12,13]$, will not be discussed in the current review. Thus, the objective of this 


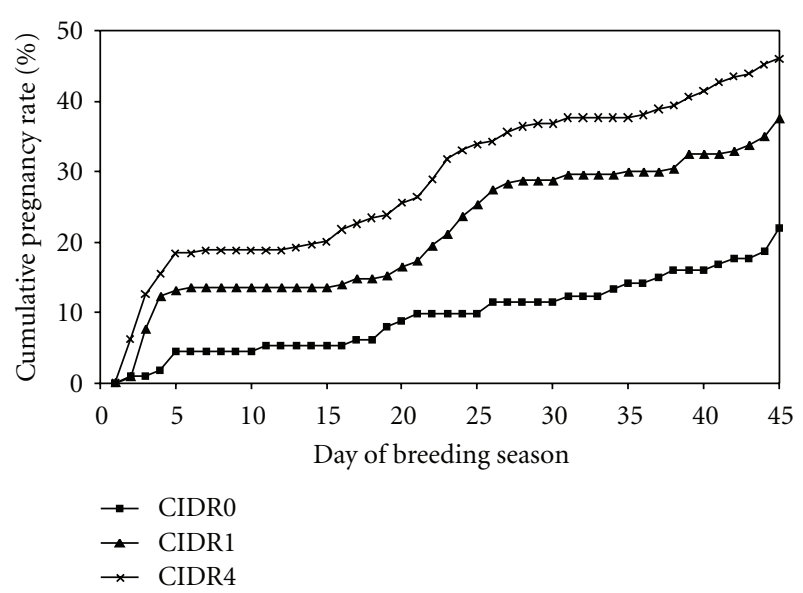

Figure 1: Cumulative percentage of pregnancy in prepubertal Bos indicus heifers throughout a $45 \mathrm{~d}$ AI breeding season. Heifers were assigned to receive, between $\mathrm{d}-12$ and 0 , no treatment (CIDR0), a new intravaginal insert (CIDR1), or a similar intravaginal insert that had previously been used three times (CIDR4). Heifers were artificially inseminated 10 to $14 \mathrm{~h}$ after detection of estrus; those that returned in estrus after the first service were re-inseminated. Adapted from Claro Júnior et al. [15].

manuscript is to discuss some pharmacological and management strategies to improve reproductive performance in cow-calf enterprises from tropical areas.

\section{Resolution of the Reproductive Challenges in Bos indicus Females}

2.1. Anestrus and Estrus Detection. The anovulatory conditions in cattle were reviewed [14], and it appears that the underlying physiology for anovulation is similar for postpartum cows and prepubertal heifers. In these circumstances, there are waves of ovarian follicular development, preceded by an increase in peripheral FSH concentrations, that progress through to follicle deviation. However, in these animals, their hypothalamus is sensitive to estradiol negative feedback on LH pulses; therefore, low peripheral estradiol concentrations, perhaps derived from dominant ovarian follicle, suppressed LH pulses, and limited growth and estradiol production by the follicle, thereby preventing an LH surge and ovulation. The high hypothalamic sensitivity to estradiol is associated with an increased expression of estradiol receptors in the anterior and medial basal hypothalamus, which declines gradually after parturition or as puberty approaches.

Nutrition is one of the primary factors affecting resumption to cyclicity in cattle, since inadequate energy status may intensify the negative feedback effect of the estradiol on LH secretion [16]. There is a number of studies demonstrating that cows beginning the BS with a low body condition score (BCS) or losing BCS during the BS, both indicatives of poor nutrition, are less likely to show estrous behavior and to conceive $[4,17-20]$. Nutritional strategies to reduce the length of postpartum anestrus will not be discussed in the present manuscript, but the importance of this issue imposes breeders to provide adequate levels of nutrition for cows to express their reproductive potential. However, even when an adequate nutrition is offered, the offspringto-dam interactions, such as touch, auditory, visual, and olfactory communications, decrease LH secretion and delay resumption to cyclicity in suckled cattle [21]. Interestingly, a short-term temporary weaning (TW; $48 \mathrm{~h}$ ) increased LH pulse frequency to levels similar to those in proestrus $[22,23]$ and improved the rates of estrous detection [4] and ovulation in response to exogenous GnRH [24] in postpartum anestrous cows, indicating that strategies to increase the frequency of LH pulses are effective in inducing ovulation in noncycling cattle.

Another approach that has been successfully used for induction of cyclicity in cattle is the treatment with intravaginal inserts that release exogenous progesterone ( $\mathrm{P} 4[4$, 17-20]). In noncycling cows, treatment with progestogens increased LH secretion $[23,25]$, which is critical for resumption of cyclicity, and reduced the occurrence of premature luteolysis after first postpartum ovulation [4], enabling estrous behavior [15] and pregnancy establishment [4]. Because P4 inhibits estradiol receptors in several tissues $[26,27]$, it is likely that expression of hypothalamic estradiol receptors is decreased when cattle are given exogenous P4, thereby reducing the estradiol negative feedback on $\mathrm{LH}$ secretion [28]. Moreover, a short luteal phase usually occurs after first postpartum ovulation, which is another factor contributing to low reproductive efficiency in beef cows, and treatment with $\mathrm{P} 4$ prior to first postpartum ovulation consistently reduced the occurrence of premature luteolysis [29]. Based on the rationale that strategies to increase the frequency of LH pulses improve fertility, Vasconcelos et al. [4] evaluate effects of treatments with an intravaginal insert containing $1.9 \mathrm{~g}$ of P4 (CIDR, Pfizer Animal Health, São Paulo, SP, Brazil) and/or $48 \mathrm{~h}$ TW on reproductive performance of postpartum anestrous crossbred Nelore (Bos indicus $) \times$ Angus $($ Bos taurus $)$ cows $(n=286)$ throughout the BS. Experimental groups consisted in (1) no treatment; (2) $48 \mathrm{~h}$ TW beginning on d 0 of BS; (3) CIDR device between $\mathrm{d}-7$ and 0 of BS; (4) CIDR device between d-7 and 0 of BS followed by $48 \mathrm{~h}$ TW. Artificial inseminations following detection of estrous behavior were performed between $\mathrm{d} 0$ and 25 of BS, and cows were submitted to natural service between d 26 and 80 of BS. Results are shown in Table 1. Detection of estrus rates during the first $3 \mathrm{~d}$ and within 25 days of BS were higher in cows receiving TW and conception rate in cows inseminated in the first $3 \mathrm{~d}$ of BS was greater in cows treated with P4. Combining P4 with TW increased pregnancy rate in the first $3 \mathrm{~d}$ and in $25 \mathrm{~d}$ of BS, but pregnancy rate at the end of BS did not differ among treatment groups. Therefore, combining P4 with TW improved the percentage of cows becoming pregnant at the beginning of the BS by direct benefits on estrus detection and conception rates. Despite effectiveness in inducing cyclicity in postpartum cows, the treatments described above have the inconvenience of being dependent on estrus detection, which is a limiting factor in Bos indicus cattle, as previously discussed. 
TABle 1: Percentage of cows inseminated (first $3 \mathrm{~d}$ and $25 \mathrm{~d}$ of breeding season), conception (first $3 \mathrm{~d}$ and from $\mathrm{d} 4$ to 25 of breeding season) and pregnancy rates (first $3 \mathrm{~d}, 25 \mathrm{~d}$, and in $80 \mathrm{~d}$ of breeding season) in anestrous Nelore (Bos indicus) $\times$ Angus (Bos taurus) crossbred cows treated or not treated with an intravaginal insert containing $1.9 \mathrm{~g}$ of progesterone (CIDR) between days -7 to 0 of breeding season and/or $48 \mathrm{~h}$ temporary weaning (TW) between $\mathrm{d} 0$ and 2 of breeding season. Adapted from Vasconcelos et al. [4].

\begin{tabular}{lcccc}
\hline \multirow{2}{*}{ Dependent variable } & \multicolumn{2}{c}{ Without CIDR } & \multicolumn{2}{c}{ With CIDR } \\
& Without TW & With TW & Without TW & With TW \\
\hline \% cows inseminated $(3 \mathrm{~d})^{\mathrm{bc}}$ & $2.7 \%(2 / 73)$ & $48.6 \%(34 / 70)$ & $17.8 \%(13 / 73)$ & $41.4 \%(29 / 70)$ \\
Conception $(3 \mathrm{~d})^{\mathrm{ac}}$ & $50.0 \%(1 / 2)$ & $8.8 \%(3 / 34)$ & $46.1 \%(6 / 13)$ & $58.6 \%(17 / 29)$ \\
${\text { Pregnancy rate }(3 \mathrm{~d})^{\mathrm{ab}}}_{\text {Conception }(4-25 \mathrm{~d})}$ & $1.4 \%(1 / 73)$ & $4.3 \%(3 / 70)$ & $8.2 \%(6 / 73)$ & $24.3 \%(17 / 70)$ \\
$\%$ cows inseminated $(25 \mathrm{~d})^{\mathrm{b}}$ & $50.0 \%(7 / 14)$ & $16.7 \%(2 / 12)$ & $50.0 \%(4 / 8)$ & $60.0 \%(3 / 5)$ \\
Pregnancy rate $(25 \mathrm{~d})^{\mathrm{ac}}$ & $21.9 \%(16 / 73)$ & $60.0 \%(42 / 70)$ & $28.8 \%(21 / 73)$ & $48.6 \%(34 / 70)$ \\
Pregnancy rate $(80 \mathrm{~d})$ & $10.9 \%(8 / 73)$ & $7.1 \%(5 / 70)$ & $13.7 \%(10 / 73)$ & $28.6 \%(20 / 70)$ \\
\hline
\end{tabular}

${ }^{\mathrm{a}} \mathrm{CIDR}(P<.05)$; ${ }^{\mathrm{T}} \mathrm{TW}(P<.05) ;{ }^{\mathrm{c}} \mathrm{CIDR} \times \mathrm{TW}(P<.05)$.

Treatments developed since the last decade have precisely controlled follicular and luteal development, as well as ovulation, allowing AI without the need for detection of estrus (i.e., fixed-time AI; TAI) and regardless of cycling status. Because the main challenges of cattle under tropical climates are the long length of postpartum acyclicity and the low estrus detection rates, these protocols for synchronization of ovulation can have large positive impacts on reproductive efficiency of beef cattle. Three steps are necessary for the success of a synchronization of ovulation protocol. First, a new follicular wave has to be recruited in manner to group follicles of all cows at a similar and known stage of development. Currently, there are two main pharmacological approaches to synchronize the emergence of a new follicular wave during synchronization of ovulation protocols: (1) inducing ovulation of the dominant follicle by administration of gonadotropins or gonadotropin released hormone (GnRH; e.g., Ovsynch protocol [30]), or (2) inducing follicular atresia by administration of estrogens associated with P4 [31]. Protocols using P4 + estradiol are less expensive and have been shown to be more efficient in postpartum cows under tropical climates than those based on synchronization of follicular wave emergence with $\mathrm{GnRH}$ [32]; the reason for this difference and other particularities of these two approaches will be further discussed. The second step of a synchronization of ovulation protocol is a decrease in circulating concentrations of $\mathrm{P} 4$ for the beginning of proestrus and development of the ovulatory follicle, which can be performed by induction of luteolysis with prostaglandin F2 $\alpha$ (PGF2 $\alpha$ ) analogues, such as dinoprost or cloprostenol, and by the withdrawal of P4 inserts. When cow is known to be in anestrus, treatments with PGF2 $\alpha$ analogues are not necessary, since a corpus luteum (CL) is not present; however, at most times, it is not practical to evaluate the presence of CL in every treated cow, so luteolytic drugs must be administered to all animals. One important characteristic to be considered is that PGF $2 \alpha$ treatment is ineffective in inducing luteolysis during the first $5 \mathrm{~d}$ of estrous cycle [33] and, therefore, the treatments with P4 inserts for at least $6 \mathrm{~d}$ prior to administration of PGF $2 \alpha$ ensures that all cows have a CL with luteolytic capacity, improving the likelihood of response to the treatment. In Bos indicus cows with a CL older than $7 \mathrm{~d}$, a $50 \%$ reduction in the recommended dose of dinoprost tromethamine $(12.5 \mathrm{mg})$ when administered intramuscularly was as effective in causing luteolysis as the standard recommended dose $(25 \mathrm{mg}$; Table 2 [17]).

Induction of ovulation is the third step of a TAI protocol and can be performed with drugs that aim to cause ovulation of potential preovulatory follicles. Induction of ovulation can be achieved using hormones such as human chorionic gonadotrophin (hCG) or luteinizing hormone (LH), which act directly on follicles, or hormones that induce a preovulatory surge of LH such as GnRH or esters of estradiol. However, because intervals between injection and ovulation vary for each product, a special care must be taken to schedule the protocol in a manner to inseminate cows at a proper time relative to ovulation. Previous studies have indicated that replacing GnRH by esters of estradiol in TAI protocols results in similar pregnancy rates. For example, pregnancy rates in Bos indicus cows receiving GnRH-based protocols did not differ when ovulatory stimulus after luteolysis was GnRH or estradiol benzoate (EB [34]). In another study with protocols using $\mathrm{P} 4$ associated with estradiol in Bos indicus cows, EB, estradiol cypionate (ECP), and GnRH resulted in similar synchronization, conception, and pregnancy rates (Table 2 [17]). Because ECP is less expensive than $\mathrm{GnRH}$ treatment and time of administration requires less labor than does $\mathrm{EB}$ treatment (EB treatment has to be administered $24 \mathrm{~h}$ after P4 insert withdrawal and $30 \mathrm{~h}$ before TAI, requiring cows to be handled once more than in ECP and GnRH treatments), ECP treatment, administered concurrently with $\mathrm{P} 4$ insert withdrawal and $48 \mathrm{~h}$ before TAI, was indicated by the authors as the ovulatory stimulus to be used in synchronization protocols in Bos indicus cows. It is important to note that the efficiency of the second and third steps is closely related to the efficacy of the first step of a synchronization of ovulation protocol. Thus, TAI protocols using different approaches for synchronizing the follicular wave will be discussed in more detail. 
TABLE 2: Ovulation, conception, and pregnancy rates of suckled Bos indicus cows submitted to a synchronization of ovulation protocol using progesterone associated with estradiol having different dosages of PGF2 $\alpha$ (Study 1), ovulatory stimuli (Study 2), and uses of intravaginal progesterone insert (Study 3 and 4). Adapted from Meneghetti et al. [17].

\begin{tabular}{|c|c|c|c|}
\hline Item & Ovulation rate & Conception rate & Pregnancy rate \\
\hline \multicolumn{4}{|c|}{ Study 1-PGF2 $\alpha$ dosage ${ }^{\mathrm{a}}$} \\
\hline Half-dose & $88.7 \%(110 / 124)$ & $69.2 \%(76 / 110)$ & $61.3 \%(76 / 124)$ \\
\hline Full-dose & $94.4 \%(119 / 126)$ & $68.2 \%(81 / 119)$ & $64.3 \%(81 / 126)$ \\
\hline \multicolumn{4}{|c|}{ Study 2-Ovulatory stimulus ${ }^{\mathrm{b}}$} \\
\hline ECP & $89.5 \%(282 / 315)$ & $56.7 \%(160 / 282)$ & $50.8 \%(160 / 315)$ \\
\hline $\mathrm{EB}$ & $90.9 \%(289 / 318)$ & $57.1 \%(165 / 289)$ & $51.9 \%(165 / 318)$ \\
\hline GnRH & $91.0 \%(284 / 312)$ & $59.5 \%(169 / 284)$ & $54.2 \%(169 / 312)$ \\
\hline \multicolumn{4}{|c|}{ Study 3-CIDR uses ${ }^{\mathrm{c}}$} \\
\hline CIDRn & $91.7 \%(496 / 541)$ & $56.0 \%(278 / 496)$ & $51.4 \%(278 / 541)$ \\
\hline CIDR9d & $90.6 \%(482 / 532)$ & $59.3 \%(286 / 482)$ & $53.8 \%(286 / 532)$ \\
\hline CIDR18d & $90.1 \%(373 / 414)$ & $55.8 \%(208 / 373)$ & $50.2 \%(208 / 414)$ \\
\hline \multicolumn{4}{|c|}{ Study 4-CIDR uses ${ }^{\mathrm{c}}$} \\
\hline CIDRn & $79.7 \%(55 / 69)$ & $54.5 \%(30 / 55)$ & $43.5 \%(30 / 69)$ \\
\hline CIDR9d & $80.0 \%(144 / 180)$ & $61.1 \%(88 / 114)$ & $48.9 \%(88 / 180)$ \\
\hline CIDR18d & $83.9 \%(188 / 224)$ & $60.1 \%(113 / 188)$ & $50.4 \%(113 / 224)$ \\
\hline CIDR27d & $85.7 \%(90 / 105)$ & $57.8 \%(52 / 90)$ & $49.5 \%(52 / 105)$ \\
\hline
\end{tabular}

${ }^{a}$ Cows were treated with $12.5 \mathrm{mg}$ (Half-dose) or $25 \mathrm{mg}$ (Full-dose) dinoprost tromethamine on $\mathrm{d} 7 \mathrm{of}$ a protocol using progesterone associated with benzoate estradiol. Progesterone devices were maintained between $\mathrm{d} 0$ and 9 , and fixed-time AI were performed on $\mathrm{d} 11$. Ovulation was induced with estradiol benzoate administered on $\mathrm{d} 10$. Dependent variables were not affected by PGF2 $\alpha$ dosage $(P>.10)$.

${ }^{\mathrm{b}}$ Cows were treated with estradiol cypionate (ECP) on d 9, estradiol benzoate (EB) on d 10, or gonadotropin releasing $(\mathrm{GnRH})$ hormone on d 11 relative to initiation of a protocol using progesterone associated with benzoate estradiol. Progesterone devices were maintained between $\mathrm{d} 0$ and 9 , and fixed-time AI were performed on $\mathrm{d} 11$. Dependent variables were not affected by ovulatory stimulus $(P>.10)$.

${ }^{c}$ Cows received a nonpreviously used CIDR (CIDRn), a CIDR used previously for $9 \mathrm{~d}$ (CIDR9d), a CIDR used previously for $18 \mathrm{~d}$ (CIDR18d), or a CIDR used previously for $27 \mathrm{~d}$ (CIDR27d) at initiation of the protocol. Dependent variables were not affected by CIDR type $(P>.10)$.

2.1.1. Synchronization Protocols Using Progesterone in Association with Estradiol. Treatment with P4 plus estradiol efficiently suppressed FSH and follicular growth, synchronizing follicular wave emergence in bovine females regardless of the stage of follicular development at the time of treatment [31]. Although there is a range ( 3 to $6 \mathrm{~d}$ ) in the time that follicular wave begins $[35,36]$, this treatment resulted in satisfactory results in both anestrous and cycling beef cows [37] and was more efficient in postpartum cows under tropical climates than those based on synchronization of follicular wave emergence with GnRH [32]. Furthermore, these protocols provide exogenous $\mathrm{P} 4$ necessary to prevent premature luteolysis after first postpartum ovulation. Meneghetti et al. [17] developed a synchronization of ovulation protocol for postpartum Bos indicus cows aiming to (1) synchronize follicle wave emergence with P4 plus estradiol; (2) increase dominant follicle development with an intravaginal P4 insert plus TW; (3) prevent premature luteolysis after a synchronized ovulation by treating anestrous cows before the synchronized ovulation with $\mathrm{P} 4$; (4) reduce the cost of the protocol by decreasing the dosage of PGF $2 \alpha$, replacing GnRH with estradiol as an ovulatory stimulus, and using the same P4 insert more than one time. The protocol consisted in a CIDR insertion $+2 \mathrm{mg}$ of EB on d 0 , CIDR withdrawal $+12.5 \mathrm{mg}$ of dinoprost tromethamine $+0.5 \mathrm{mg}$ of ECP + TW on d 9, TAI + reunite calves with their dams on $\mathrm{d} 11$, and resulted in synchronization rate $\sim 90 \%$ and pregnancy rate $\sim 50 \%$ (Tables 2 and 3). Moreover, with this protocol, the CIDR may be used as many as 4 times with no negative effects on pregnancy rates (Table 2 ).

In a retrospective study [18], factors affecting pregnancy rates of heifers and cows treated with the synchronization of ovulation protocol developed by Meneghetti et al. [17] were assessed. Lactating and nonlactating beef cows and heifers from various locations in Brazil during the 2006$2007(n=27,195)$ and 2007-2008 $(n=36,838)$ BS were submitted to the same basic synchronization of ovulation protocol described above. In both breeding seasons, the cattle were from the same 71 farms in 7 Brazilian states. Cows were managed according to local procedures, and in all places nutritional management was based only on grass pastures with water and appropriate ad libitum access to a mineral supplement. Each BS lasted from October until March of the following year but varied among farms. Only data from cows with no recorded reproductive abnormalities were used for analysis. Pregnancy was diagnosed by transrectal ultrasonography at 28 to $35 \mathrm{~d}$ after TAI. Pregnancy rate did not differ between BS. Grouping data from 20062007 and 2007-2008 BS, overall pregnancy rate at TAI was $49.6 \%$ (31,786/64,033). Pregnancy rate did not differ among location but varied among farm within location (results ranging between $26.8 \%$ and $68.0 \%$ ) and cow group within farms. During the 2006-2007 BS, pregnancy rate ranged from $29.5 \%$ to $40.0 \%$ at 10 farms; from $40.1 \%$ to $50.0 \%$ at 26 farms; from $50.1 \%$ to $60.0 \%$ at 30 farms; from $60.1 \%$ to $65.0 \%$ at 5 farms. During the 2007-2008 breeding season, 
pregnancy rate ranged from $26.8 \%$ to $40.0 \%$ at 11 farms; from $40.1 \%$ to $50.0 \%$ at 27 farms; from $50.1 \%$ to $60.0 \%$ at 27 farms; from $60.1 \%$ to $68.0 \%$ at 6 farms. Pregnancy rate was affected by breed (Bos indicus: 48.3\% [26,123/54,145]; Bos taurus: $61.7 \%$ [3,652/5,922]; crossbred Bos indicus $\times$ Bos taurus: $50.7 \%[2,011 / 3,966]$ ), category (nulliparous: $39.6 \%$ [2,095/5,290]; suckled primiparous: 45.2\% [3,924/8,677]; suckled multiparous: 51.8\% [24,245/46,767]; nonsuckled multiparous: $46.1 \%[1,522 / 3,299])$, BCS at TAI $(\leq 2.5: 43.0 \%$ $[3,409 / 7,923] ; 3.0: 49.6 \% \quad[18,958 / 38,229] ; \geq 3.5: 52.7 \%$ $[9,419 / 17,881])$. Days postpartum at beginning of protocol did not affect pregnancy rate $(30$ to $60 \mathrm{~d}: 47.6 \%$ [4,228/8,881]; 61 to $90 \mathrm{~d}: 51.7 \%[16,325 / 31,572] ; 91$ to $150 \mathrm{~d}$ : $50.8 \%[7,616 / 14,991])$. Pregnancy rate was also consistently affected by sire (results ranging from $7.2 \%$ to $77.3 \%$ ) and AI technician (results ranging from $15.1 \%$ to $81.8 \%$ ). Therefore, the benchmark of a $50 \%$ pregnancy rate at TAI in Bos indicus cattle was shown to be achievable with the protocol developed by Meneghetti et al. [17], and differences in breed, BCS, category, sire, and AI technician may account for some of the variation in reproductive performance that occurs between and within farms.

In another study evaluating additional strategies to improve fertility in Bos indicus cows submitted to the treatment proposed by Meneghetti et al. [17], the treatment with 400 IU equine chorionic gonadotropin (eCG), but not with $\mathrm{FSH}$, was shown to improve pregnancy rates in postpartum cows similarly to TW (Table 3 [18]). The length of the half-life of eCG is relatively long [38], and it has the capacity to bind to both $\mathrm{LH}$ and FSH receptors [39], which may stimulate theca and granulosa cells of the dominant follicle [40] and also P4 secretion by the early corpus luteum [32]. It is likely that eCG treatment potentially improves follicular development and provides a more adequate endocrine environment during proestrus (greater circulating estradiol concentrations) and diestrus (greater circulating P4 concentrations), which is favorable for fertility. Interestingly, treatments with either 200 or $400 \mathrm{IU}$ eCG did not improve conception or pregnancy rates in cows that were temporarily weaned (Table $3[18]$ ), indicating that TW likely stimulated adequate secretion of $\mathrm{LH}$ in a manner that additional gonadotropin support may not be required for final follicular development. Thus, the protocol using P4 plus estradiol in postpartum Bos indicus cows must be associated with TW or eCG, but not with both.

2.1.2. Synchronization Protocols Using GnRH. Protocols using GnRH and PGF2 $\alpha$ have afforded acceptable results in Bos taurus females (pregnancy rate $>50 \%[41,42]$ ), but lower pregnancy rates have been reported for Bos indicus cows $[24,34,43]$. However, a commercial source of estradiol is not available for estrous cycle manipulation in many countries so other products (e.g., GnRH, LH, or hCG) have been used to induce ovulation of dominant follicles and follicular wave synchronization. The mechanism by which $\mathrm{GnRH}$ induces new wave emergence is based on inducing ovulation of dominant follicles, and its success is dependent on the presence of a dominant follicle with ovulatory capacity at the time of treatment, which is acquired when ovarian follicles are $>8.5 \mathrm{~mm}$ in diameter in Bos indicus cattle [13]. In cows ovulating to the $\mathrm{GnRH}$ treatment, the emergence of a new follicular wave was described to occur within $2 \mathrm{~d}$ [44]. The induction of ovulation in a high percentage of treated cows at the start of treatment is critical for obtaining satisfactory results, as shown previously in dairy cattle [45]. However, the likelihood of ovulation to a $\mathrm{GnRH}$ treatment is lower in anestrous than in cycling cows [24, 46], because follicles become atresic in a short time after the acquisition of ovulatory capacity [14]. Furthermore, anestrous cows that do not ovulate to the first ovulatory stimulus but ovulate to the second are likely to have premature luteolysis because ovulation occurs with no pre-exposure to P4 $[4,24,29]$. Although in GnRH-based protocols exogenous P4 can be provided between first and second ovulatory stimuli to avoid premature luteolysis, cows not ovulating to the first ovulatory stimulus do not have synchronized follicular wave, reducing the probability of success of the protocol [24, 45]. These are some of the reasons why TAI protocols using P4 + estradiol have been shown to be more efficient in postpartum cows under tropical climates than those based on synchronization of follicular wave emergence with $\mathrm{GnRH}$ [32], and highlight the importance of the ovulation to the first ovulatory stimulus for the success of these protocols.

In a series of two studies in suckled Bos indicus cows (Experiment 1: $n=139$; Experiment 2: $n=376$ ) submitted to a GnRH-based protocol for synchronization of ovulation, the effects of TW $(48 \mathrm{~h})$ prior to each ovulatory stimulus were evaluated [24]. Treatments consisted in $\mathrm{GnRH}$ on $\mathrm{d}$ 0 followed by PGF $2 \alpha$ on $\mathrm{d} 7$ and EB on $\mathrm{d} 8$, and cows undergoing TW or not before GnRH (TW1) and/or TW after PGF2 $\alpha$ (TW2). In Experiment 1, anestrous cows receiving TW1 had greater follicular diameter on d 0 (10.6 versus $9.9 \mathrm{~mm}$ ) and greater ovulation rate to $\mathrm{GnRH}$ treatment (85.4 versus $49.0 \%$ ) than cows not receiving, whereas in cycling cows, there was no effect of TW1 on those dependent variables. Regardless of cyclicity, cows receiving TW2 had larger follicular diameter on d 9 (10.8 versus $10.4 \mathrm{~mm})$ and greater ovulation rate to EB treatment (79.1 versus $58.3 \%$ ) than cows not receiving TW1. In Experiment 2, pregnancy rates at TAI, which was performed $30 \mathrm{~h}$ after EB treatment, were greater in cows receiving both TW1 and TW2 than in those not receiving TW1 and TW2 (29.8 versus $10.6 \%$ ). Thus, the inclusion of TW in strategic times of GnRH-based protocols may improve fertility by causing an increase on follicular development and ovulation rates.

When circulating concentrations of P4 are maintained between 1 and $2 \mathrm{ng} / \mathrm{mL}$, the period of dominant follicle growth is prolonged due to an increase on the frequency of LH pulses [47]. Based on this rationale, it is plausible to speculate that prolonged treatments with $\mathrm{P} 4$ in anestrous cows may have beneficial effects of follicular development and, consequently, on the likelihood of ovulation to a $\mathrm{GnRH}$ treatment. Sá Filho et al. [48] evaluated treatments with P4 and TW to increase the size of follicle prior to the first ovulatory stimulus of a GnRH-based protocol in Bos indicus cows $(n=283)$ and, based on their results, indicated the following protocol: CIDR insertion on $\mathrm{d} 0$ (am), CIDR 
TABLE 3: Ovulation, conception, and pregnancy rates of suckled Bos indicus cows submitted to a synchronization of ovulation protocol using progesterone associated with estradiol having different strategies to improve fertility. Adapted from Sá Filho et al. [18].

\begin{tabular}{|c|c|c|c|}
\hline Item & Ovulation rate & Conception rate & Pregnancy rate \\
\hline \multicolumn{4}{|c|}{ Study 1-eCG to replace TW ${ }^{\mathrm{a}}$} \\
\hline Control & $81.9 \%(181 / 221)$ & $50.8 \%(92 / 181)$ & $41.6 \%(92 / 221)$ \\
\hline eCG300 & $80.8 \%(168 / 208)$ & $57.7 \%(97 / 168)$ & $46.6 \%(97 / 208)$ \\
\hline eCG400 & $83.9 \%(187 / 223)$ & $64.7 \%(121 / 187)$ & $54.3 \%(121 / 223)$ \\
\hline TW & $86.6 \%(207 / 239)$ & $59.4 \%(123 / 207)$ & $51.5 \%(123 / 239)$ \\
\hline \multicolumn{4}{|c|}{ Study $2-\mathrm{FSH}$ to replace $\mathrm{eCG}^{\mathrm{b}}$} \\
\hline TW & - & - & $41.9 \%(83 / 198)$ \\
\hline eCG400 & - & - & $43.3 \%(81 / 187)$ \\
\hline Folltropin & - & - & $34.3 \%(74 / 216)$ \\
\hline Pluset & - & - & $32.1 \%(36 / 112)$ \\
\hline \multicolumn{4}{|c|}{ Study 3-eCG associated with $\mathrm{TW}^{\mathrm{c}}$} \\
\hline TW & $88.9 \%(264 / 297)$ & $158 / 264(59.8)$ & $53.2 \%(158 / 297)$ \\
\hline TW + eCG200 & $93.0 \%(278 / 299)$ & $155 / 278(55.7)$ & $51.8 \%(155 / 299)$ \\
\hline TW + eCG400 & $90.0 \%(261 / 291)$ & $152 / 261(58.2)$ & $52.2 \%(152 / 291)$ \\
\hline
\end{tabular}

${ }^{a}$ Cows received no treatment (Control), 300 IU of eCG (eCG300), 400 IU of eCG (eCG400), or temporary weaning (48 h; TW) on d 9 relative to initiation of an ovulation synchronization protocol. Pregnancy rates were greater in eCG400 and TW treatments than in Control $(P<.05)$.

${ }^{b}$ Cows received temporary weaning ( $48 \mathrm{~h}$; TW), $400 \mathrm{IU}$ of eCG (eCG400), $20 \mathrm{mg}$ of Folltropin (Folltropin-FSH), or $20 \mathrm{mg}$ of Pluset (Pluset-FSH) on d 9 relative to initiation of an ovulation synchronization protocol. Pregnancy rates were greater in eCG400 and TW treatments than in Folltropin and Pluset $(P<.05)$.

${ }^{\mathrm{c} C o w s}$ received temporary weaning (48 h; TW), temporary weaning + $200 \mathrm{IU}$ of eCG (TW + eCG200), or temporary weaning + 400 IU of eCG (TW + eCG400) on d 9 relative to initiation of an ovulation synchronization protocol. Dependent variables were not affected by treatments $(P>.10)$.

withdrawal + TW on d $7(\mathrm{am}), \mathrm{GnRH}+$ reunite calves with their dams on $\mathrm{d} 9(\mathrm{am}), \mathrm{PGF} 2 \alpha+\mathrm{TW}$ on $\mathrm{d} 15(\mathrm{pm})$, and TAI $+\mathrm{GnRH}+$ reunite calves with their dams on $\mathrm{d} 17(\mathrm{pm})$. This protocol resulted in $94.4 \%$ of ovulation in response to the first GnRH treatment, $95.8 \%$ of ovulation in response to the second GnRH treatment, and rates of conception (number of pregnant cows divided by the number of ovulated cows) and pregnancy (number of pregnant cows divided by the number of treated cows) of $55.1 \%$ and $52.8 \%$, respectively [48]. These rates are greater than previous reports in beef cows, and synchronized ovulation rates to the second $\mathrm{GnRH}$ injection were similar between anestrous and cycling cows. In another experiment presented in the same manuscript, Sá Filho et al. [48] compared the effects of the inclusion of a CIDR between first GnRH and PGF2 $\alpha$ treatments of a synchronization protocol consisting of TW on d 0 , GnRH + reunite calves with their dams on d 2, PGF $2 \alpha+$ TW on d 8, and TAI + GnRH + reunite calves with their dams on d 10, however, pregnancy rates were similar between cows receiving (28.5\% [43/151]) and not receiving a CIDR (32.7\% [49/150]). Because treatments with exogenous P4 associated with GnRH-based synchronization protocols were described to improve fertility in anestrous Bos taurus females [41, 42] and $51 \%$ of cows in the study of Sá Filho et al. [48] were cycling, further studies are required for a better knowledge of the feasibility of this type of treatment in anestrous Bos indicus cattle.

\subsection{Special Circumstances}

2.2.1. Prepubertal Heifers. In cow-calf enterprises using Bos indicus breeds, it is relatively common to find heifers with age and body weight adequate for the establishment of puberty, but that are still prepubertal. The key factor responsible for establishment of puberty is an increase in $\mathrm{LH}$ release from the anterior pituitary, in response to GnRH from the hypothalamus [49]. Treatment for $12 \mathrm{~d}$ with a new CIDR or a CIDR that had previously been used three times, with each use occurring for $9 \mathrm{~d}$, hastened puberty and improved estrus detection and pregnancy rates at the beginning of the BS in prepubertal Bos indicus heifers (Figure 1 [15]). However, the use of a CIDR that had previously been used three times resulted in greater follicular diameter at the end of treatments, conception in $7 \mathrm{~d}$ of BS, and pregnancy rate in $45 \mathrm{~d}$ of breeding than the treatment with a new CIDR (Table 4 [15]). Thus, a previously used CIDR insert is preferable to a new CIDR to induce puberty and improve reproductive performance during the BS in prepubertal Bos indicus heifers. Furthermore, in prepubertal Bos indicus heifers with adequate age and puberty, the treatment with P4 for $12 \mathrm{~d}$ may be used prior to the synchronization of ovulation, aiming to increase the percentage of cycling animals at the beginning of treatments.

\subsubsection{Pubertal Nulliparous Heifers and Nonlactating Cycling} Cows. In cycling cattle treated with exogenous sources of $\mathrm{P} 4$, such as CIDR inserts, circulating concentrations of P4, that are a result of the $\mathrm{P} 4$ released by the $\mathrm{CL}+$ the $\mathrm{P} 4$ released by the insert, may be elevated to levels above the optimal. For instance, TAI protocols in Bos indicus postpuberal heifers and nonlactating cows have resulted in lower pregnancy rates than in anestrous cows $[18,50]$. Carvalho et al. [51] and Meneghetti et al. [17] found negative effects of elevated circulating concentrations of P4 during 
TABle 4: Reproductive endpoints in prepubertal Bos indicus heifers that received, between d-12 and 0, no treatment (CIDR0), a new intravaginal insert containing $1.9 \mathrm{~g}$ of progesterone (CIDR1), or a similar intravaginal insert that had previously been used three times (CIDR4). The breeding season started on $\mathrm{d} 1$ and consisted of AI after estrus detection between $\mathrm{d} 1$ and 45 and exposure to bulls between $\mathrm{d}$ 46 and 90. Adapted from Claro Júnior et al. [15].

\begin{tabular}{|c|c|c|c|}
\hline \multirow{2}{*}{ Dependent variable } & \multicolumn{3}{|c|}{ Treatment } \\
\hline & CIDR0 & CIDR1 & CIDR4 \\
\hline Progesterone on $\mathrm{d} 0, \mathrm{ng} / \mathrm{mL}^{\mathrm{a}}$ & $0.37 \pm 0.16$ & $2.31 \pm 0.11$ & $1.20 \pm 0.11$ \\
\hline Follicle diameter on $\mathrm{d} 0, \mathrm{~mm}^{\mathrm{a}}$ & $9.45 \pm 0.24$ & $9.72 \pm 0.17$ & $11.42 \pm 0.16$ \\
\hline Uterine score on $\mathrm{d} 0^{\mathrm{a}}$ & $1.49 \pm 0.06$ & $1.88 \pm 0.04$ & $2.24 \pm 0.04$ \\
\hline Interval to estrus, $\mathrm{d}^{\mathrm{a}}$ & $4.4 \pm 0.28$ & $3.48 \pm 0.13$ & $3.24 \pm 0.14$ \\
\hline Estrus detection in $7 \mathrm{~d}, \%(\mathrm{n})^{\mathrm{a}}$ & $19.5(22 / 113)$ & $42.6(101 / 237)$ & $39.3(94 / 239)$ \\
\hline Conception rate in $7 \mathrm{~d}, \%(\mathrm{n})^{\mathrm{a}}$ & $27.3(6 / 22)$ & $33.7(34 / 101)$ & $46.8(44 / 94)$ \\
\hline Pregnancy rate in $7 \mathrm{~d}, \%(\mathrm{n})^{\mathrm{a}}$ & $5.3(6 / 113)$ & $14.3(34 / 237)$ & $18.4(44 / 239)$ \\
\hline Estrus detection in $45 \mathrm{~d}, \%(\mathrm{n})^{\mathrm{a}}$ & $52.2(59 / 113)$ & $72.1(171 / 237)$ & $75.3(180 / 239)$ \\
\hline Pregnancy rate in $45 \mathrm{~d}, \%(\mathrm{n})^{\mathrm{a}}$ & $27.4(31 / 113)$ & $39.2(93 / 237)$ & $47.7(114 / 239)$ \\
\hline Pregnancy rate in $90 \mathrm{~d}, \%(\mathrm{n})^{\mathrm{a}}$ & $72.6(82 / 113)$ & $83.5(198 / 237)$ & $83.7(200 / 239)$ \\
\hline
\end{tabular}

${ }^{a}$ Treatment $(P<.05)$.

the synchronization protocols on fertility in cattle, probably because high circulating concentrations of progesterone during the protocols reduced LH pulse frequency [52] and inhibited dominant follicle development [47] . Peres et al. [53] evaluated strategies to increase fertility of Bos indicus postpubertal heifers and nonlactating cows submitted to a fixed-time artificial insemination (TAI) protocol consisting of a CIDR insertion + EB on d 0, CIDR withdrawal + ECP on $\mathrm{d} 9$, and TAI on Day 11. In the first study, pubertal heifers $(n=1,153)$ received a new or an 18 -d previously used CIDR and, on d 9, PGF $2 \alpha+0,200$, or 300 IU eCG. Heifers treated with a new CIDR had greater serum concentration of P4 on d $9(3.06 \pm 0.09$ versus $2.53 \pm 0.09 \mathrm{ng} / \mathrm{mL})$ and a smaller follicle at TAI $(11.61 \pm 0.11$ versus $12.05 \pm 0.12 \mathrm{~mm})$. Heifers with smaller follicles at TAI had lesser serum progesterone concentrations on d 18 and reduced rates of ovulation, conception, and pregnancy $(P<.05)$. Treatment with eCG improved follicle diameter at TAI $(11.50 \pm 0.10,11.90 \pm 0.11$, and $12.00 \pm 0.10 \mathrm{~mm}$ for 0,100 , and $200 \mathrm{IU}$, resp.), serum P4 concentration on $\mathrm{d} 18(2.77 \pm 0.11,3.81 \pm 0.11$, and $4.87 \pm$ $0.11 \mathrm{ng} / \mathrm{mL}$ ), and the rates of ovulation, and pregnancy rate (Table 5 [53]). In a further study, nonlactating Bos indicus cows $(n=702)$ received PGF $2 \alpha$ treatment on $\mathrm{d} 7$ or 9 and, on d 9, 0 or 300 IU eCG. Cows receiving PGF $2 \alpha$ on $\mathrm{d} 7$ had lesser serum $\mathrm{P} 4$ concentrations on $\mathrm{d} 9(3.05 \pm 0.21$ versus $4.58 \pm 0.21 \mathrm{ng} / \mathrm{mL})$, a larger follicle at TAI $(11.54 \pm 0.21$ versus $10.84 \pm 0.21 \mathrm{~mm} ; P<.05)$, and improved rates of ovulation, conception, and pregnancy (Table 5 [53]). Treatment with eCG improved serum P4 concentration on d 18 (3.24 \pm 0.14 versus $4.55 \pm 0.14 \mathrm{ng} / \mathrm{mL}$ ) and the rates of ovulation and pregnancy (Table $5[53]$ ). Thus, giving PGF $2 \alpha$ earlier in the protocol and eCG treatment may improved fertility of cycling cattle submitted to TAI protocols using P4 associated with estradiol.

2.2.3. First-Calving Cows. As previously discussed, the intake of nutrients during the postpartum period in primiparous cows is not sufficient to meet requirements for growth as well as lactation. This characteristic of first-calving cows contribute to a condition of deep postpartum anestrus and for poor pregnancy rates in primiparous cows, such that many producers maintain nonpregnant primiparous cows in their herds to be inseminated during the subsequent BS. Before the decade of 1990, when treatments for induction of cyclicity had not been well developed yet, many producers in Brazil adopted the strategy of beginning the BS in heifers BS earlier than in cows, in manner to permit heifers to calve earlier and have more d postpartum at the subsequent BS. With this management, producers assumed that primiparous cows with greater d postpartum were more likely to spontaneously resume estrous cyclicity, having a greater likelihood of pregnancy in BS using natural service or conventional AI.

Primiparous cows experience a dramatic linear decrease on BCS during the first postpartum months. Because BCS is one of the primary factors affecting the probability of pregnancy in TAI protocols, Meneghetti and Vasconcelos [3] hypothesized that a longer interval between calving and TAI could be deleterious to fertility in primiparous cows. In their study in Brazil, Meneghetti and Vasconcelos [3] observed that crossbred Nelore $\times$ Angus heifers $(n=155)$ calving in September, October, and November had a reduction of 0.84 , 0.53 , and 0.17 points, respectively, in their BCS (scale from 1 to 5) from calving to December; in this same study, Bos indicus heifers calving in September, October, and November experienced a reduction of $0.86,0.47$, and 0.17 points in their BCS from calving to December [3]. Thus, d postpartum was negatively related with BCS regardless of genetic group. Moreover, authors found a lower pregnancy rate in cows ( $n=538)$ with lower BCS, and this effect occurred regardless of genetic group or synchronization protocol (P4 + estradiol or GnRH-based). Therefore, in ranches using TAI in primiparous cows, it is not recommended to anticipate heifers BS, and TAI protocols must be started as soon as $30 \mathrm{~d}$ postpartum for cows to be AI before a loss of BCS. It is important to consider that this effects was observed in 
TABLE 5: Ovulation, conception, and pregnancy rates of Bos indicus pubertal heifers (Study 1) and nonlactating cows (Study 2) submitted to a synchronization of ovulation protocol using progesterone associated with estradiol having different strategies to improve fertility. Adapted from Peres et al. [53].

\begin{tabular}{llll}
\hline Item & Ovulation rate & Conception rate & Pregnancy rate \\
\hline Study 1-CIDR uses and eCG ${ }^{\mathrm{a}}$ & & & \\
$\quad$ CIDR 1st use/0 IU eCG & $84.3 \%(161 / 191)$ & $49.1 \%(79 / 161)$ & $41.4 \%(79 / 191)$ \\
CIDR 1st use/200 IU eCG & $89.9 \%(169 / 188)$ & $51.5 \%(87 / 169)$ & $46.3 \%(87 / 188)$ \\
CIDR 1st use/300 IU eCG & $94.6 \%(177 / 187)$ & $52.0 \%(92 / 177)$ & $49.2 \%(92 / 187)$ \\
CIDR 3rd use/0 IU eCG & $83.4 \%(176 / 211)$ & $49.4 \%(87 / 176)$ & $41.2 \%(87 / 211)$ \\
CIDR 3rd use/200 IU eCG & $87.2 \%(170 / 195)$ & $54.7 \%(93 / 170)$ & $47.7 \%(93 / 195)$ \\
CIDR 3rd use/300 IU eCG & $93.9 \%(170 / 185)$ & $47.1 \%(80 / 170)$ & $44.2 \%(80 / 181)$ \\
Study 2-Time of PGF2 $\alpha$ treatment and eCG & & & \\
PGF2 $\alpha$ d 7/0 IU eCG & & $59.4 \%(85 / 143)$ & $57.7 \%(85 / 178)$ \\
PGF2 $\alpha$ d 7/300 IU eCG & $80.3 \%(143 / 178)$ & $62.1 \%(97 / 156)$ & $27.0 \%(47 / 174)$ \\
PGF2 $\alpha$ d 9/0 IU eCG & $90.7 \%(156 / 172)$ & $42.0 \%(47 / 112)$ & $45.5 \%(81 / 178)$ \\
PGF2 $\alpha$ d 9/300 IU eCG & $64.4 \%(112 / 174)$ & $50.9 \%(81 / 159)$ & $(159 / 178)$ \\
\hline
\end{tabular}

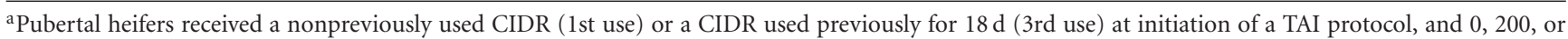
$300 \mathrm{IU}$ of eCG on d 9 relative to CIDR insertion, in a $2 \times 3$ factorial design. There were effects of eCG treatment on ovulation, conception, and pregnancy rates $(P<.05)$.

${ }^{b}$ Nonlactating cows were treated with $12.5 \mathrm{mg}$ of dinoprost tromethamine on d 7 ( 48 h before CIDR withdrawal; PGF $2 \alpha \mathrm{d} 7$ ) or on d 9 (immediately after CIDR withdrawal; PGF $2 \alpha$ d 9), and 0 IU of eCG or 300 IU of eCG on d 9 of an ovulation synchronization protocol. There were effects of time of PGF2 $\alpha$ treatment on ovulation, conception, and pregnancy rates $(P<.05)$; eCG affected ovulation and pregnancy rates $(P<.05)$.

the central Brazil, where the weather is characterized by two distinct seasons (a rainy season, from October to March, and a dry season, from April to September, in manner that during the dry season and beginning of rainy season, pastures have forage with low quantity and quality (high lignin; low protein). The characteristics of each region may contribute for a more or a less severe negative effect of $d$ postpartum on fertility of primiparous cows submitted TAI protocols, and this must be considered for producers.

2.2.4. Ranches Using Natural Service. Although the synchronization of ovulation technique has resolved some challenges of the tropical cattle and allowed producers to inseminate a greater percentage of their cows, more than $90 \%$ of bovine females in tropical areas are bred by natural service. Besides the fact that ranching in these areas is often extensive, which difficult the adoption of reproductive biotechnologies such as TAI, unfortunately many producers view these advances either as not needed, as not feasible, and(or) as uneconomical. Therefore, sometimes inefficiencies in Bos indicus beef cattle are restricted more by geography, environment, economics, and social traditions of the producers than by biologic factors.

As previously discussed, combining pretreatment with P4/progestogens and TW enhanced the proportion of postpartum cows that exhibited estrus behavior and conceived during a BS [4]. Melengestrol acetate-based protocols are useful tools to be used in conjunction with natural service mating systems for beef cows because oral administration of the progestin is practical and requires limited management of the animals. Sá Filho et al. [19] proposed a protocol that effectively induced estrous cyclicity among Bos indicus anestrous cows, synchronized estrus activity, and prevented premature luteolysis with no negative effect on conception.
The protocol consisted in $0.5 \mathrm{mg} / \mathrm{d}$ of melengestrol acetate between d-14 and $-1 ; 2.0 \mathrm{mg}$ i.m. injection of ECP on d9; $48 \mathrm{~h}$ TW between $\mathrm{d} 0$ and 2, natural service beginning on d 0. In postpartum Bos indicus cattle treated with this protocol, pregnancy rates in 10,40 , and $70 \mathrm{~d}$ of BS were, respectively, $38.2 \%$ (100/262), 56.9\% (149/262), and 67.6\% (177/262), whereas in nontreated cows (Control), these rates were $11.0 \%$ (27/245), 36.7\% (90/245), and 64.5\% (158/245), respectively. Therefore, even in systems using less technology, it is possible to improve fertility of cows receiving natural service, by induction of cyclicity with this simple treatment.

\section{Conclusions}

Currently, there are hormonal treatments allowing producers to reach the benchmark of $50 \%$ of pregnancy rate at TAI and increase the percentage of cows becoming pregnant by AI at the beginning of the BS. Thus, ranches have optimized labor and increased the weight at weaning of the calves by assembling genetic improvement and concentrating births to the most adequate season. In Bos indicus cattle, protocols must provide a source of exogenous $\mathrm{P} 4$ and stimulate the final development of the dominant follicle. In postpartum cattle, this stimulus may be provided by TW or eCG treatment, whereas in nonlactating cycling cattle that may be provided by eCG or advancing the time of PGF2 $\alpha$ treatment. The particularities within the Bos indicus genetic group must be considered for the decision about what protocol will result in better pregnancy rates. Regardless of synchronization protocol, differences in BCS, category, sire, and AI technician may account for some of the variation in reproductive performance that occurs between and within farms, and should be always considered to anticipate and improve results. 


\section{References}

[1] O. L. Pinheiro, C. M. Barros, R. A. Figueiredo, E. R. Do Valle, R. O. Encarnação, and C. R. Padovani, "Estrous behavior and the estrus-to-ovulation interval in nelore cattle (Bos indicus) with natural estrus or estrus induced with prostaglandin $F 2 \alpha$ or norgestomet and estradiol valerate," Theriogenology, vol. 49, no. 3, pp. 667-681, 1998.

[2] H. Abeygunawardena and C. M. B. Dematawewa, "Prepubertal and postpartum anestrus in tropical Zebu cattle," Animal Reproduction Science, vol. 82-83, pp. 373-387, 2004.

[3] M. Meneghetti and J. L.M. Vasconcelos, "Calving date, body condition score, and response to a timed artificial insemination protocol in first-calving beef cows," Brazilian Journal of Veterinary and Animal Sciences, vol. 60, no. 4, pp. 786-793, 2008.

[4] J. L. M. Vasconcelos, O. G. Sá Filho, G. C. Perez, and A. T. N. Silva, "Intravaginal progesterone device and/or temporary weaning on reproductive performance of anestrous crossbred Angus $\times$ Nelore cows," Animal Reproduction Science, vol. 111, no. 2-4, pp. 302-311, 2009.

[5] H. Dobson and M. Kamonpatana, "A review of female cattle reproduction with special reference to a comparison between buffaloes, cows and zebu," Journal of Reproduction and Fertility, vol. 77, no. 1, pp. 1-36, 1986.

[6] D. J. Patterson, L. R. Corah, J. R. Brethour et al., "Evaluation of reproductive traits in Bos taurus and Bos indicus crossbred heifers: effects of postweaning energy manipulation," Journal of Animal Science, vol. 69, no. 6, pp. 2349-2361, 1991.

[7] J. Restle, V. A. Polli, and D. B. De Senna, "Effect of genetic group and heterosis on age and weight at puberty, and on reproductive performance of beef heifers," Pesquisa Agropecuária Brasileira, vol. 34, pp. 701-707, 1999.

[8] R. A. Figueiredo, C. M. Barros, O. L. Pinheiro, and J. M. P. Soler, "Ovarian follicular dynamics in Nelore breed (Bos indicus)," Theriogenology, vol. 47, no. 8, pp. 1489-1505, 1997.

[9] E. C. Segerson, T. R. Hansen, D. W. Libby, R. D. Randel, and W. R. Getz, "Ovarian and uterine morphology and function in Angus and Brahman cows," Journal of Animal Science, vol. 59, no. 4, pp. 1026-1046, 1984.

[10] J. Buratini Jr., C. A. Price, J. A. Visintin, and G. A. Bó, "Effects of dominant follicle aspiration and treatment with recombinant bovine somatotropin (BST) on ovarian follicular development in Nelore (Bos indicus) heifers," Theriogenology, vol. 54, no. 3, pp. 421-431, 2000.

[11] E. S. Sartorelli, L. M. Carvalho, D. R. Bergfelt, O. J. Ginther, and C. M. Barros, "Morphological characterization of follicle deviation in Nelore (Bos indicus) heifers and cows," Theriogenology, vol. 63, no. 9, pp. 2382-2394, 2005.

[12] R. Sartori, P. M. Fricke, J. C. P. Ferreira, O. J. Ginther, and M. C. Wiltbank, "Follicular deviation and acquisition of ovulatory capacity in bovine follicles," Biology of Reproduction, vol. 65, no. 5, pp. 1403-1409, 2001.

[13] L. U. Gimenes, M. F. Sá Filho, N. A. T. Carvalho et al., "Follicle deviation and ovulatory capacity in Bos indicus heifers," Theriogenology, vol. 69, no. 7, pp. 852-858, 2008.

[14] M. C. Wiltbank, A. Gümen, and R. Sartori, "Physiological classification of anovulatory conditions in cattle," Theriogenology, vol. 57, no. 1, pp. 21-52, 2002.

[15] I. Claro Júnior, O. G. Sá Filho, R. F. G. Peres, F. H. S. Aono, M. L. Day, and J. L. M. Vasconcelos, "Reproductive performance of prepubertal Bos indicus heifers after progesterone-based treatments," Theriogenology, vol. 74, no. 6, pp. 903-911, 2010.
[16] R. D. Randel, "Nutrition and postpartum rebreeding in cattle," Journal of Animal Science, vol. 68, no. 3, pp. 853-862, 1990.

[17] M. Meneghetti, O. G. Sá Filho, R. F. G. Peres, G. C. Lamb, and J. L. M. Vasconcelos, "Fixed-time artificial insemination with estradiol and progesterone for Bos indicus cows I: basis for development of protocols," Theriogenology, vol. 72, no. 2, pp. 179-189, 2009.

[18] O. G. Sá Filho, M. Meneghetti, R. F. G. Peres, G. C. Lamb, and J. L. M. Vasconcelos, "Fixed-time artificial insemination with estradiol and progesterone for Bos indicus cows II: strategies and factors affecting fertility," Theriogenology, vol. 72, no. 2, pp. 210-218, 2009.

[19] O. G. Sá Filho, D. J. Patterson, and J. L. Vasconcelos, "Development of estrous synchronization protocols using melengestrol acetate in Bos indicus cattle," Journal of Animal Science, vol. 87, no. 6, pp. 1981-1990, 2009.

[20] O. G. Sá Filho, C. C. Dias, G. C. Lamb, and J. L.M. Vasconcelos, "Progesterone-based estrous synchronization protocols in non-suckled and suckled primiparous Bos indicus beef cows," Animal Reproduction Science, vol. 119, no. 1-2, pp. 9-16, 2010.

[21] J. S. Stevenson, E. L. Knoppel, J. E. Minton, B. E. Salfen, and H. A. Garverick, "Estrus, ovulation, luteinizing hormone, and suckling-induced hormones in mastectomized cows with and without unrestricted presence of the calf," Journal of Animal Science, vol. 72, no. 3, pp. 690-699, 1994.

[22] S. Edwards, "The effects of short term calf removal on pulsatile LH secretion in the postpartum beef cow," Theriogenology, vol. 23, no. 5, pp. 777-785, 1985.

[23] G. L. Williams, F. Talavera, B. J. Petersen, J. D. Kirsch, and J. E. Tilton, "Coincident secretion of follicle-stimulating hormone and luteinizing hormone in early postpartum beef cows: effects of suckling and low-level increases of systemic progesterone," Biology of Reproduction, vol. 29, no. 2, pp. 362373, 1983.

[24] J. L.M. Vasconcelos, E. R. Vilela, and O. G. Sá Filho, “Temporary weaning at two different times of the GnRH-PGF $F_{2 \alpha}-\mathrm{EB}$ synchronization of ovulation protocol in post partum Nelore cows," Brazilian Journal of Veterinary and Animal Sciences, vol. 61, no. 1, pp. 95-103, 2009.

[25] M. Garcia-Winder, P. E. Lewis, E. C. Townsend, and E. K. Inskeep, "Effects of norgestomet on follicular development in postpartum beef cows," Journal of Animal Science, vol. 64, no. 4, pp. 1099-1109, 1987.

[26] A. J. W. Hsueh, E. J. Peck Jr., and J. H. Clark, "Control of uterine estrogen receptor levels by progesterone," Endocrinology, vol. 98, no. 2, pp. 438-444, 1976.

[27] E. J. Pavlik and P. B. Coulson, "Modulation of estrogen receptors in four different target tissues. Differential effects of estrogen vs progesterone," Journal of Steroid Biochemistry, vol. 7, no. 5, pp. 369-376, 1976.

[28] M. L. Day and L. H. Anderson, "Current concepts on the control of puberty in cattle," Journal of Animal Science, vol. 76, pp. 1-15, 1998.

[29] O. G. Sá Filho, W. W. Thatcher, and J. L. M. Vasconcelos, "Effect of progesterone and/or estradiol treatments prior to induction of ovulation on subsequent luteal lifespan in anestrous Nelore cows," Animal Reproduction Science, vol. 112, no. 1-2, pp. 95-106, 2009.

[30] J. R. Pursley, M. O. Mee, and M. C. Wiltbank, "Synchronization of ovulation in dairy cows using PGF $2 \alpha$ and GnRH," Theriogenology, vol. 44, no. 7, pp. 915-923, 1995.

[31] G. A. Bo, G. P. Adams, R. A. Pierson, H. E. Tribulo, M. Caccia, and R. J. Mapletoft, "Follicular wave dynamics after 
estradiol-17 $\beta$ treatment of heifers with or without a progestogen implant," Theriogenology, vol. 41, no. 8, pp. 1555-1569, 1994.

[32] P. S. Baruselli, E. L. Reis, M. O. Marques, L. F. Nasser, and G. A. Bó, "The use of hormonal treatments to improve reproductive performance of anestrous beef cattle in tropical climates," Animal Reproduction Science, vol. 82-83, pp. 479-486, 2004.

[33] D. M. Henricks, J. T. Long, J. R. Hill, and J. F. Dickey, "The effect of prostaglandin $\mathrm{F}_{2 \alpha}$ during various stages of the oestrous cycle of beef heifers," Journal of Reproduction and Fertility, vol. 41, no. 1, pp. 113-120, 1974.

[34] C. M. Barros, M. B. P. Moreira, R. A. Figueiredo, A. B. Teixeira, and L. A. Trinca, "Synchronization of ovulation in beef cows (Bos indicus) using GnRH, PGF2 $\alpha$ and estradiol benzoate," Theriogenology, vol. 53, no. 5, pp. 1121-1134, 2000.

[35] U.-H. Kim, G.-H. Suh, H.-W. Nam, H.-G. Kang, and I.H. Kim, "Follicular wave emergence, luteal function and synchrony of ovulation following $\mathrm{GnRH}$ or estradiol benzoate in a CIDR-treated, lactating Holstein cows," Theriogenology, vol. 63, no. 1, pp. 260-268, 2005.

[36] M. F. Martinez, G. P. Adams, J. P. Kastelic, D. R. Bergfelt, and R. J. Mapletoft, "Induction of follicular wave emergence for estrus synchronization and artificial insemination in heifers," Theriogenology, vol. 54, no. 5, pp. 757-769, 2000.

[37] F. M. Rhodes, C. R. Burke, B. A. Clark, M. L. Day, and K. L. Macmillan, "Effect of treatment with progesterone and oestradiol benzoate on ovarian follicular turnover in postpartum anoestrous cows and cows which have resumed oestrous cycles," Animal Reproduction Science, vol. 69, no. 3-4, pp. 139-150, 2002.

[38] T. D. Carruthers, "Principles of hormone therapy in theriogenology," in Current Therapy in Theriogenology 2. Diagnosis, Treatment and Prevention of Reproductive Diseases in Small and Large Animals, D. A. Morrow, Ed., p. 4, W. B. Saunders, 1986.

[39] B. D. Murphy and S. D. Martinuk, "Equine chorionic gonadotropin," Endocrine Reviews, vol. 12, no. 1, pp. 27-44, 1991.

[40] M. Kuran, J. S. M. Hutchinson, and P. J. Broadbent, "The response of bovine granulosa cells to different gonadotrophins in culture," Animal Reproduction Science, vol. 45, no. 1-2, pp. $1-12,1996$.

[41] G. C. Lamb, J. S. Stevenson, D. J. Kesler, H. A. Garverick, D. R. Brown, and B. E. Salfen, "Inclusion of an intravaginal progesterone insert plus $\mathrm{GnRH}$ and prostaglandin $\mathrm{F}_{2 \alpha}$ for ovulation control in postpartum suckled beef cows," Journal of Animal Science, vol. 79, no. 9, pp. 2253-2259, 2001.

[42] J. E. Larson, G. C. Lamb, J. S. Stevenson et al., "Synchronization of estrus in suckled beef cows for detected estrus and artificial insemination and timed artificial insemination using gonadotropin-releasing hormone, prostaglandin $\mathrm{F}_{2 \alpha}$, and progesterone," Journal of Animal Science, vol. 84, no. 2, pp. 332-342, 2006.

[43] J. P. Saldarriaga, D. A. Cooper, J. A. Cartmill, J. F. Zuluaga, R. L. Stanko, and G. L. Williams, "Ovarian, hormonal, and reproductive events associated with synchronization of ovulation and timed appointment breeding of Bos indicus-influenced cattle using intravaginal progesterone, gonadotropin-releasing hormone, and prostaglandin $\mathrm{F}_{2 \alpha}$," Journal of Animal Science, vol. 85, no. 1, pp. 151-162, 2007.

[44] G. A. Bó, P. S. Baruselli, D. Moreno et al., "The control of follicular wave development for self-appointed embryo transfer programs in cattle," Theriogenology, vol. 57, no. 1, pp. 53-72, 2002.
[45] J. L. M. Vasconcelos, R. W. Silcox, G. J. M. Rosa, J. R. Pursley, and M. C. Wiltbank, "Synchronization rate, size of the ovulatory follicle, and pregnancy rate after synchronization of ovulation beginning on different days of the estrous cycle in lactating dairy cows," Theriogenology, vol. 52, no. 6, pp. 10671078, 1999.

[46] P. Fernandes, A. B. Teixeira, A. J. Crocci, and C. M. Barros, "Timed artificial insemination in beef cattle using $\mathrm{GnRH}$ agonist, PGF2alpha and estradiol benzoate," Theriogenology, vol. 55, no. 7, pp. 1521-1532, 2001.

[47] A. E. Stock and J. E. Fortune, "Ovarian follicular dominance in cattle: relationship between prolonged growth of the ovulatory follicle and endocrine parameters," Endocrinology, vol. 132, no. 3, pp. 1108-1114, 1993.

[48] O. G. Sá Filho, E. R. Vilela, T. W. Geary, and J. L. M. Vasconcelos, "Strategies to improve fertility in postpartum multiparous Bos indicus cows submitted to a fixed-time insemination protocol with gonadotropin-releasing hormone and prostaglandin $\mathrm{F}_{2 \alpha}$," Journal of Animal Science, vol. 87, no. 9, pp. 2806-2814, 2009.

[49] M. L. Day, K. Imakawa, P. L. Wolfe, R. J. Kittok, and J. E. Kinder, "Endocrine mechanisms of puberty in heifers. Role of hypothalamo-pituitary estradiol receptors in the negative feedback of estradiol on luteinizing hormone secretion," Biology of Reproduction, vol. 37, no. 5, pp. 1054-1065, 1987.

[50] C. C. Dias, F. S. Wechsler, M. L. Day, and J. L. M. Vasconcelos, "Progesterone concentrations, exogenous equine chorionic gonadotropin, and timing of prostaglandin $\mathrm{F}_{2 \alpha}$ treatment affect fertility in postpuberal Nelore heifers," Theriogenology, vol. 72, no. 3, pp. 378-385, 2009.

[51] J. B. P. Carvalho, N. A. T. Carvalho, E. L. Reis, M. Nichi, A. H. Souza, and P. S. Baruselli, "Effect of early luteolysis in progesterone-based timed AI protocols in Bos indicus, Bos indicus $\times$ Bos taurus, and Bos taurus heifers," Theriogenology, vol. 69, no. 2, pp. 167-175, 2008.

[52] M. S. Roberson, M. W. Wolfe, T. T. Stumpf, R. J. Kittok, and J. E. Kinder, "Luteinizing hormone secretion and corpus luteum function in cows receiving two levels of progesterone," Biology of Reproduction, vol. 41, no. 6, pp. 997-1003, 1989.

[53] R. F. G. Peres, I. C. Júnior, O. G. Sá Filho, G. P. Nogueira, and J. L. M. Vasconcelos, "Strategies to improve fertility in Bos indicus postpubertal heifers and nonlactating cows submitted to fixed-time artificial insemination," Theriogenology, vol. 72, no. 5, pp. 681-689, 2009. 

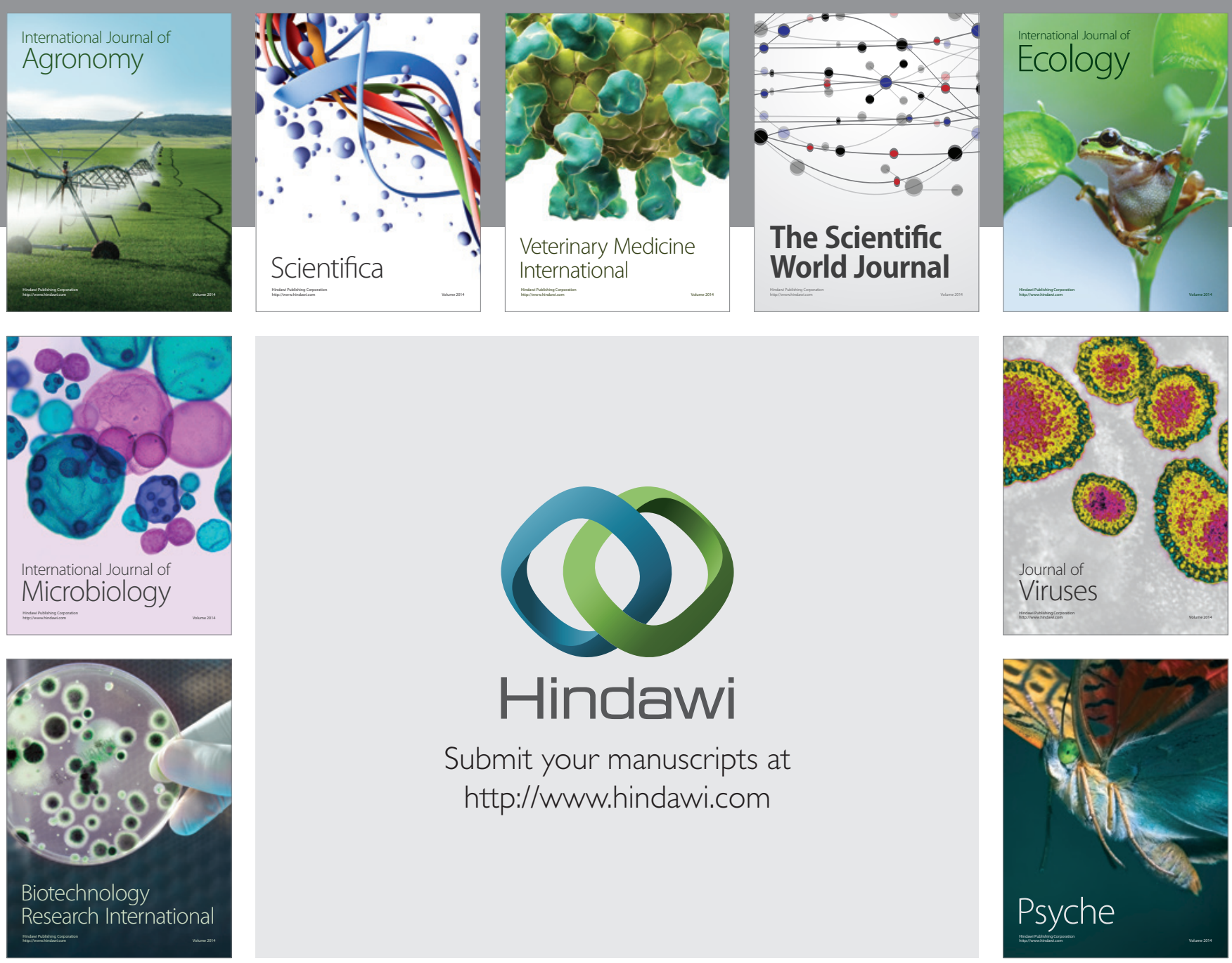

Submit your manuscripts at

http://www.hindawi.com
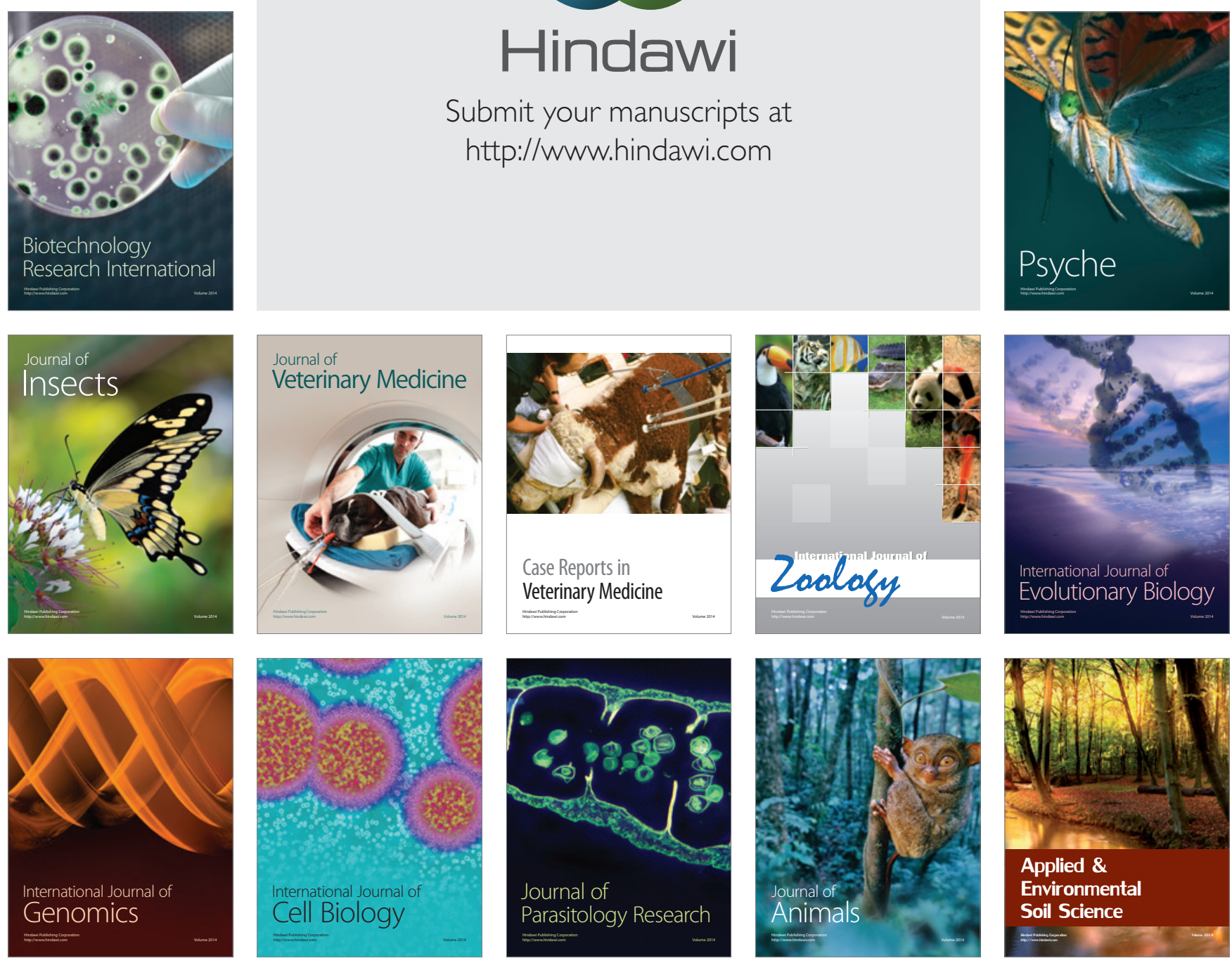